SHORT COMMUNICATION

\title{
The role of seed mass on the caching decision by agoutis, Dasyprocta leporina (Rodentia: Agoutidae)
}

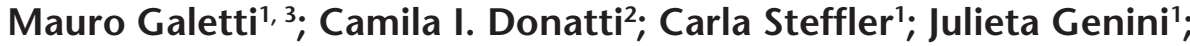 \\ Ricardo S. Bovendorp ${ }^{1} \&$ Marina Fleury ${ }^{1}$
}

\author{
${ }^{1}$ Laboratório de Biologia da Conservação, Departamento de Ecologia, Universidade Estadual Paulista. Caixa Postal 199, \\ 13506-900 Rio Claro, São Paulo, Brazil. \\ 2 Department of Biology, Stanford University, Stanford, CA, USA. \\ ${ }^{3}$ Corresponding Author. E-mail: mgaletti@rc.unesp.br
}

\begin{abstract}
It has been shown that the local extinction of large-bodied frugivores may cause cascading consequences for plant recruitment and overall plant diversity. However, to what extent the resilient mammals can compensate the role of seed dispersal in defaunated sites is poorly understood. Caviomorph rodents, especially Dasyprocta spp., are usually resilient frugivores in hunted forests and their seed caching behavior may be important for many plant species which lack primary dispersers. We compared the effect of the variation in seed mass of six vertebrate-dispersed plant species on the caching decision by the red-rumped agoutis Dasyprocta leporina Linnaeus, 1758 in a land-bridge island of the Atlantic forest, Brazil. We found a strong positive effect of seed mass on seed fate and dispersal distance, but there was a great variation between species. Agoutis never cached seeds smaller than $0.9 \mathrm{~g}$ and larger seeds were dispersed for longer distances. Therefore, agoutis can be important seed dispersers of large-seeded species in defaunated forests.
\end{abstract}

KEY WORDS. Astrocaryum; defaunation; Ilha Anchieta; palms; scatter hoarding.

The local extinction of large-bodied frugivores, especially tapirs, peccaries, and large primates, has cascading consequences for plant recruitment and overall plant diversity (Dirzo et al. 2007, Dirzo \& Miranda 1991, Muller-Landau 2007, Terborgh et al. 2008). The intensity of poaching in each mammal community and the intrinsic characteristics of these species determine the resilient species that will thrive in the area (Peres 2000). However, to what extent the resilient seed dispersers, which usually comprise small species, can inherit the major role of seed dispersal in defaunated sites is poorly understood (DONATTI et al. 2009).

Small and medium-sized rodents are the major candidates to compensate the lack of large seed dispersers because they are less negatively affected by hunting or fragmentation (WRIGHT 2003). Several species of Neotropical rodents hoard fruits from locally abundant fruiting trees for future consumption, which in turn will also promote seed dispersal if some of the cached seeds are left intact (VANDER WALL 1990). In the Neotropics, large caviomorph rodents, such agoutis (Dasyprocta spp.) and acouchies (Myoprocta spp.) are considered the most important scatter hoarders, especially of large seeds (AsQuith et al. 1999, Forget 1991, Forget et al. 1999, Galetti et al. 2006, Peres \& Baider 1997). In fact, it is assumed that the extinction of several largebodied frugivorous mammals (megafauna) during the late Pleis- tocene has left agoutis as the inheritors of dispersal of several large fleshy-fruited species (Guimaraes et al. 2008, Hallwachs 1986). Agoutis are rarely extirpated by hunting in the Amazon (Peres 2000), have been observed in highly fragmented landscapes (Jorge 2008) and, consequently, can be one of the last seed dispersers of large-seeded species in fragmented or defaunated areas (Asquith et al. 1999, Pimentel \& Tabarelli 2004). It is estimated that one third of all palm species are dispersed by scatter-hoarding rodents, especially agoutis in the Brazilian Atlantic forest (GaletTi et al. 2006). Therefore, it is crucial to understand the decision behavior of agoutis when they find a seed.

The probability of seed dispersal by agoutis is affected by both seed availability and seed traits, such as seed mass and the presence of secondary compounds in the seeds (FORGET et al. 2002, JANSEN et al. 2004, Guimarães et al. 2003). However, most experiments on seed dispersal by caviomorph rodents have been done with large seeds and focused on seed mass variation within species (JANSEN et al. 2004, but see Forget et al. 1998). In addition, most of studies were carried out in areas with several sympatric scatter-hoarding species, such as squirrels (Sciurus spp.), spiny rats (Proechimys spp. and Trinomys spp.) and species of Dasyproctidae (Myoprocta spp. and Dasyprocta spp.), making it difficult to identify the disperser (FORGET 1990, FORGET et al. 1998). Therefore, it is important to disentangle the caching behavior 
of each rodent species if we want to predict the potential consequences of defaunation on plant regeneration (Dirzo et al. 2007).

In this study, we carried out field experiments to test the selective pressure on seed dispersal or predation by red-rumped agoutis - Dasyprocta leporina (Linnaeus, 1758) - and dispersal distance on different plant species along a gradient of both seed mass and density of agoutis. We quantified the fate (cached or preyed upon) and dispersal distance of six plant species with various seed mass offered to red-rumped agoutis.

This study was carried out at Ilha Anchieta (Anchieta hereafter; $45^{\circ} 02^{\prime}-45^{\circ} 04^{\prime} \mathrm{W}, 23^{\circ} 27^{\prime}-23^{\circ} 34^{\prime} \mathrm{S}$ ) in Ubatuba, the northeastern state of São Paulo, southeastern Brazil. Anchieta, an 826 ha land bridge island, separated from the continent by approximately $540 \mathrm{~m}$, suffered from intense human occupation in the past until it was transformed into a protected park in 1972. Currently, 70\% of its area is covered by native secondary rainforest (Alvarez et al. 2008, FAdin et al. 2009). In this area, agoutis (D. leporina) reach a very high density and are the dominant scatter hoarder (1.97 individuals/ha; Bovendorp \& GaletTi 2007). Anchieta lacks squirrels (Sciurus spp.) and the abundance of spiny rats - Trinomys iheringi Thomas, 1911 is exceptionally low (only nine individuals in 9,125 trap nights, R. S. BovendorP AND C. L. Neves, unpublished data). Pacas (Cuniculus paca Linnaeus, 1766) are also rare in Anchieta (0.06 individuals/ha, C. F. Esteves unpub. data) and are mostly seed predators (ВЕСК-KING et al. 1999). Therefore, Anchieta provides an unique opportunity to understand the caching behavior of agoutis.

We experimentally assessed the seed fate of six plant species within a range of seed masses that vary from $0.3 \mathrm{~g}$ to 25.37 g (Tab. I). All of the studied plant species annually produce fleshy fruits and do not present mast fruiting (Genini et al. 2009, Morellato et al. 2000).

Astrocaryum aculeatissimum (Schoot) Burret,1934 has simple or multiple $4-8 \mathrm{~m}$ high stems, the fruits are light brown ranging from $3.0-4.5 \mathrm{~cm}$ in length, $3.0-3.5 \mathrm{~cm}$ in diameter, with a mean seed weight of $11.43 \pm 2.40(\mathrm{~N}=130)$. At Anchieta, due to the low density of spiny rats, agoutis are the main seed dispersers of this palm (GALETTI et al. 2006). GENINI et al. (2009) found a fruit production of $1.6 \mathrm{~kg} / \mathrm{ha} /$ year with fruits ripening from March to December, on the Anchieta Island. Syagrus pseudococos
(Raddi) Glassman, 1970 has a simple 10-15 m high stem and yellow colored fruits, which are $6-7 \mathrm{~cm}$ in length, $4 \mathrm{~cm}$ wide with a mean seed weight of $19.09 \pm 3.47(\mathrm{~N}=68)$, mainly dispersed by tapirs (Tapirus terrestris Linnaeus 1758) on pristine areas. At Anchieta, this is the most common palm, with a year long fruit production of $50 \mathrm{~kg} / \mathrm{ha} /$ year (GENINI et al. 2009). Syagrus romanzoffiana (Cham.) Glassmanm, 1968 has a solitary 7-15 m high and yellow-orange fruits, which are $2-3 \mathrm{~cm}$ in length, 1-2 $\mathrm{cm}$ in diameter with a mean seed weight of $1.67 \pm 0.41(\mathrm{~N}=30)$. The $S$. romanzoffiana fruits are dispersed by primates, ungulates, carnivores, and squirrels on non-defaunated areas (GALETTI et al. 2001). At Anchieta, this palm produces $36.6 \mathrm{~kg} / \mathrm{ha} /$ year of fruits which ripen from March to July (GeninI et al. 2009). Euterpe edulis Mart., 1823 has solitary 5-12 m high stems and black-purple drupes which are 1-1.4 cm in length, and have a mean seed weight of $0.81 \pm 0.38(\mathrm{~N}=30)$. These fruits are dispersed by medium and large frugivorous birds but also by carnivores and tapirs in highly conserved areas (GALETTI et al. 1999). At Anchieta, this palm produces $13.8 \mathrm{~kg} / \mathrm{ha} /$ year of fruits which ripen from March to April (GeninI et al. 2009). The Chinese fan-palm Livistona chinensis (Jac.) R. Br. ex Mart. is an introduced species which, in Anchieta, is locally common around old human settlements. Its average fruit weight is $1.14 \pm 0.90 \mathrm{~g}$ and has only one seed, producing fruits all year round. The jackfruit, Artocarpus heterophyllus (Moraceae) Lam., 1789, is a common semi-domesticated species introduced in Anchieta. Its fruit weighs up to $12 \mathrm{~kg}$ and can bear more than 200 ovoid seeds with a mean seed weight of $5.28 \pm$ $1.36(\mathrm{~N}=315)$, which ripens from January to March. Tegu lizards, coatis, and capuchin monkeys are the main seed dispersers of jackfruits at Anchieta Island (Leslie Calderón, UNESP, unpub. data).

Fruits from these six plant species were collected from several individuals in Anchieta, the pulp was manually removed and the seeds were visually inspected for insect infestations. We discarded seeds that could be potentially infested by insects. However, insect predation on palm seeds is extremely low at Anchieta probably due to their high seed removal by agoutis (DonATTI et al. 2009).

We assessed the fate of seeds by drilling them, attaching threads to the seeds and following their fate through a modifi-

Table I. Characteristics of the seed species used in the experiments and proportion of seeds cached and preyed upon by red-rumped agoutis, D. leporina, at Anchieta Island, Brazil.

\begin{tabular}{clclccc}
\hline Family & \multicolumn{1}{c}{ Species } & Seed mass $(\mathrm{g})$ & \multicolumn{1}{c}{ Primary Disperser } & Study month & \% Cached & \% Preyed upon \\
\hline Arecaceae & Euterpe edulis & $0.81 \pm 0.38$ & Birds & March & 0 & 100 \\
Arecaceae & Syagrus romanzoffiana & $1.67 \pm 0.41$ & Foxes, monkeys, tapirs & March & 0 & 100 \\
Arecaceae & Syagrus pseudococos & $19.09 \pm 3.47$ & Tapirs & January & 41 & 59 \\
Arecaceae & Astrocaryum aculeatissimum & $11.43 \pm 2.40$ & Agoutis & February & 66 & 34 \\
Arecaceae & Livistona chinensis & $1.14 \pm 0.90$ & Birds & June & March & 20 \\
Moraceae & Artocarpus heterophylus & $5.28 \pm 1.36$ & Tegu, monkeys & 95.6 & 80 \\
\hline
\end{tabular}


cation of the spool and line method (GALETTI et al. 2006). Each seed was threaded with a line spool that was placed inside a small box, allowing the line to easily unroll when the seed was removed. Five of these boxes (each with one seed attached) were fixed in one tree representing one experimental station. Each experimental station was placed beneath a randomly selected fruiting tree and located along one of the four trails of the island. Agoutis are not able to visit more than one trail due to their relatively small home range, especially in Anchieta where the density of agoutis is very high (Bovendorp \& GALETTI 2007, Aliaga-Rossel et al. 2008) and due to the long distance between trails (one kilometer in average).

The experiments were carried out between 2005 and 2008. We used 180 seeds of Euterpe edulis (in March 2007), 180 seeds of Syagrus romanzoffiana (March, 2007), 81 seeds of Syagrus pseudococos (January, 2006), 264 seeds of Artocarpus heterophyllus (March, 2007), 109 seeds of Astrocaryum aculeatissimum, (February, 2006), and 105 seeds of Livistona chinensis (October, 2007) to run the experiments. All experiments were done in the peak of overall fruiting season at Anchieta, from January to March (GENINI et al. 2009), except for L. chinensis.

The adult palms or jackfruit trees used in the experiment were at least $50 \mathrm{~m}$ from one another. From three to five seeds were placed below a fruiting tree on the forest floor. When we could not find enough fruiting trees, we placed the seeds at the same $50 \mathrm{~m}$ intervals. We searched the area and followed the threads to locate the seeds after five days (Donatri et al. 2009). To avoid the effects of the availability of other fruit species in the seed removal of our marked seeds, we searched for other fruit species four meters around each experimental station. However, we did not find any correlation between the seed removal rate of the marked seeds in our experimental stations and the number of other zoochoric fruits around these plots, probably due to the extremely low fruit productivity at Anchieta (GENINI et al. 2009).

We chose a spool line method because previous studies showed that rodents rarely carry seeds over long distances and this method does not influence the behavior of agouti seed removal (ForgET 1991, 1990). Removed seeds were categorized as either preyed on or dispersed (cached). Seeds that were dispersed far from the experimental stations but not cached were not considered in our analysis. Endocarps with damaged seeds were easily recognized as being preyed on by agoutis, based on teeth marks, whereas dispersed seeds were found intact cached (buried). Agoutis are the only species able to scatter hoard seeds in soil at Anchieta, as squirrels are locally extinct and spiny rats, which are extremely rare in the island, cache seeds below litter (Forget 1991, DonatTi et al. 2009). Only five seeds (0.61\%) were dispersed by spiny rats (i.e. they were cached in the litter), and they were discarded from our analyses.

Agoutis were censused using standard line transect techniques (Bovendorp \& GaLETTI 2007). We walked $296 \mathrm{~km}$ along four established trails (Sul, Leste, Pedra do Navio, and Saco
Grande) which vary in length from 1.5 to $3.5 \mathrm{~km}$. We walked $123 \mathrm{~km}$ in the dry season (Winter) and $173 \mathrm{~km}$ in the wet season (Summer). The trails were walked slowly (approximately $1 \mathrm{~km} / \mathrm{h}$ ) between $6: 30$ and 11:30, 17:30 and 18:00 h. The densities and encounter rates for each trail were analyzed using the software Distance (4.1; http://www.ruwpa.st-and.ac.uk/distance) (Buckland et al. 1993, 2001).

Given that our focus is to understand if seed mass can influence the decision of agoutis towards caching or predation, the seed fate of each seed was used in the logistic regression, where seed species was considered a fixed factor. Seed fate in each location (trails) was also analyzed using a Chi-square test. All analyzes were done using R software (www.r-project.com).

We found a strong positive relationship between seed fate and seed mass (Logistic regression, $\chi^{2}=541.03, \mathrm{p}<0.0001$, Fig. 1 ), and the probability of being cached was positively related to seed mass within species (Fig. 1). All seeds weighting less than $0.9 \mathrm{~g}$ were prey upon by agoutis. Therefore, seeds of $S$. romanzoffiana and E. edulis were never cached and were preyed upon due to their small sizes. These findings were also observed on forest fragments where all E. edulis (Fleury \& GaletTI 2004) and $S$. romanzoffiana removed seeds were destroyed (FLeURY \& GALETTI 2004, 2006). On the other hand, seeds for the other three species (A. heterophyllus, A. aculeatissimum, and S. pseudococos) were cached. Forget et al. (1998) also suggest that seed mass is related to proportion of cached seeds, but although they assumed that all seeds were cached by agoutis (D. punctata), the densities of squirrels and spiny rats on their study area, Barro Colorado Island, is high (WRIGHT et al. 2000) and they could be overestimating the agouti activity as scatter hoarders.

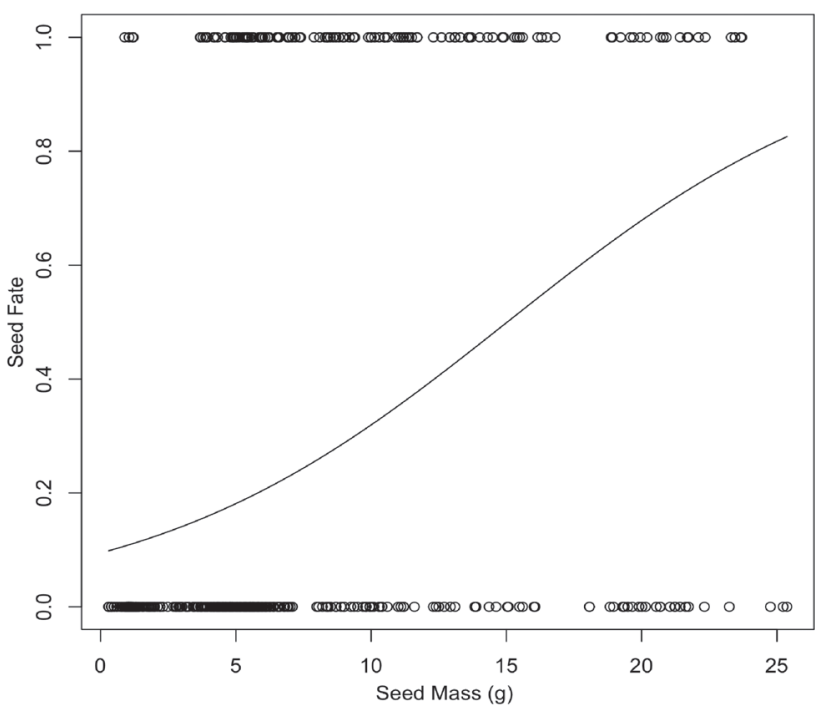

Figure 1. Logistic regression between seed mass and seed caching probability in six different tree species manipulated by red-rumped agoutis, D. leporina, at Anchieta Island, Atlantic forest, Brazil. 
The probability of a seed to be cached or preyed upon, although differing spatially $\left(\chi^{2}=28.89, \mathrm{p}<0.0001\right)$, was not related with the abundance of agoutis along the trails. However, we could compare only four trails on the entire island. DonatTI et al. (2009), comparing five areas in the Atlantic forest found that areas with intermediate densities of agoutis had higher seed dispersal of Astrocaryum aculeatissimum than areas with very low (or even extinct) or very high densities of agouties.

We found an overall positive correlation between seed mass and dispersal distance when we analyzed all the species together $\left(\mathrm{r}^{2}=0.21, \mathrm{p}<0.0001\right)$ however, within species this correlation was significant only for $A$. aculeatissimum $\left(\mathrm{r}^{2}=0.05\right.$, $\mathrm{p}=0.04)$ and $A$. heterophyllus $\left(\mathrm{r}^{2}=0.17, \mathrm{p}<0.0001\right)$, but not for S. pseudococos. JANSEN et al. (2004) found that seed mass and masting fruiting were the major determinants of seed caching by acouchies - Myoprocta acouchy Erxleben, 1777 of Carapa procera DC., 1824 Meliaceae) in French Guiana. Our data does not show that intra-specific masting was an important factor to determine seed fate, since none of our studied species present fruit masting, but overall fruit availability may have been important (Forget et al. 2002, Genini et al. 2009). Nevertheless, we do not have information on seed fate on species that ripen during the season of fruit scarcity. Secondary compounds are also another important trait for seed caching by agoutis (GUIMARÃes et al. 2003), but was not evaluated in our study.

In the Neotropics, large primates and tapirs are the major seed dispersers of large- seeded fleshy fruits (GUIMARÃes et al. 2008) and these mammals are the first to become extinct in areas with heavy hunting pressure (PEREs 2000, GALETTI et al. 2009). Although caviomorph rodents and squirrels may be the remaining dispersers of several large-seeded plants on anthropogenic environments (Pimentel \& Tabarelli 2004, Galetti et al. 2006, DonatTi et al. 2009), our data indicate that only a subsample of seed sizes will be effectively cached by agoutis.

\section{ACKNOWLEDGMENTS}

We would like to thank D. Hansen, E. Mendoza, R. Guevara and one anonymous reviewer for critical suggestions on the manuscript. To José Fragoso and Rodolfo Dirzo for discussion of the ideas in the manuscript. MG received FAPESP fellowship at Stanford University while writing this paper. RSB, JG, MF received FAPESP scholarship and research grant while doing this research. CID received a scholarship from CAPES and a grant from Fundação O Boticário de Proteção à Natureza. We also thank the Instituto Florestal for allowing us to work at Anchieta.

\section{LITERATURE CITED}

Aliaga-Rossel, E.; R.W. Kays \& J.V. Fragoso. 2008. Home-range use by the Central American agouti (Dasyprocta punctata) on Barro Colorado Island. Journal of Tropical Ecology 24: 367-374.
Alvarez, A.D.; R.S. Bovendorp; M. Fleury \& M. Galetti. 2008. Um paraíso de "exóticos". Ciência Hoje 2008: 69-71.

Asquith, N.M.; J. Terborgh; A.E. Arnold \& C.M. Riveros. 1999. The fruits the agouti ate: Hymenaea courbaril seed fate when its disperser is absent. Journal of Tropical Ecology 15: 229-235.

Beck-King, H.; O.V. Helversen \& R. Beck-King. 1999. Home range, population density, and food resources of Agouti paca (Rodentia:Agoutidae) in Costa Rica: a study using alternative methods. Biotropica 31: 675-685.

Bovendorp, R. \& M. GaletTi. 2007. Density and population size of mammals introduced on a land-bridge island in southeastern Brazil. Biological Invasions 9: 353-357.

Buckland, S.T.; D.R. Anderson; K.P. Burnham \& J.L. LaAKe. 1993. Distance sampling: estimating abundance of biological populations. London, Chapman and Hall.

Buckland, S.T.; D.R. ANDERSON; K.P. Burnham; J.L. LAAKE; D.L. BORCherS \& L. Thомаs. 2001. Introduction to Distance sampling: estimating abundance of biological populations. New York, Oxford University Press.

Dirzo, R. \& A. Miranda. 1991. Altered patterns of herbivory and diversity in the forest understory: a case study of the possible consequences of contemporary defaunation, p. 273-287. In: P.W. Price; T.M. Lewinshon; G.W. Fernandes \& W.W. Benson (Eds). Plant-animal interactions: evolutionary ecology. New York, Wiley.

Dirzo, R.; E. Mendoza \& O. OrTíz. 2007. Size-related differential seed predation in a heavily defaunated Neotropical rain forest. Biotropica 39: 355-362.

Donatti, C.I.; M. Galetti \& P.R. Guimarães. 2009. Seed dispersal and predation of an endemic Atlantic Forest palm in a gradient of seed disperser's abundance. Ecological Research 24: 1187-1195.

Fadini, R.F.; M. Fleury; C.I. Donatti \& M. Galetti. 2009. Effects of frugivore impoverishment and overabundant seed predators on the recruitment of a keystone palm. Acta Oecologica 35: 188-196.

Fleury, M. \& M. Galetti. 2004. Effects of microhabitat on palm seed predation in two forest FRAGMENTS IN SOUTHEAST BraZIL. Acta Oecologica 26: 179-184.

Fleury, M. \& M. Galetti. 2006. Forest fragment size and microhabitat effects on palm seed predation. Biological Conservation 131: 1-13.

Forget, P.M. 1990. Seed-dispersal of Vouacapoua americana (Caesalpiniaceae) by caviomorph rodents in French-Guiana. Journal of Tropical Ecology 6: 459-468.

FoRGET, P.M. 1991. Scatterhoarding of Astrocaryum paramaca by Proechimys in French Guiana: comparison with Myoprocta exilis. Tropical Ecology 32: 155-167.

Forget, P. M; F. Mercier \& F. Collinet. 1999. Spatial patterns of two rodent-dispersed rain forest trees Carapa procera (Meliaceae) and Vouacapoua americana (Caesalpiniaceae) at Paracou, French Guiana. Journal of Tropical Ecology 15: 301-313. 
Forget, P. M.; T. Milleron \& T. Feer. 1998. Patterns in post-dispersal seed removal by neotropical rodents and seed fate in relation to seed size, p. 25-49. In: D.M. Newberry; H.H.T. Prins \& N.D. BRown (Eds). Dynamics of tropical communities. Oxford, Blackwell Sciences.

Forget, P. M.; D.S. Hammond; T. Milleron \& R. Thomas. 2002. Seasonality of fruiting and food hoarding by rodents: consequences for seed dispersal and seedling recruitment, p. 379-394. In: D.J. Levey; W.R. Silva \& M. Galetti. Seed dispersal and frugivory: ecology, evolution and conservation. Wallington, $\mathrm{CAB}$ International.

Galetti, M.; V. Zipparro \& L.P. Morellato. 1999. Fruit phenology and frugivory on the palm Euterpe edulis in a lowland Atlantic forest of Brazil. Ecotropica 5: 115-122.

Galetti, M.; A. Keuroghlian; L. Hanada \& I. Morato. 2001. Frugivory and seed dispersal by the lowland tapir (Tapirus terrestris) in southeast Brazil. Biotropica 33: 723-726.

Galetti, M.; C.I. Donatti; A.S. Pires; P.R. Guimaraes \& P. Jordano. 2006. Seed survival and dispersal of an endemic Atlantic forest palm: the combined effects of defaunation and forest fragmentation. Botanical Journal of the Linnean Society 151: 141-149.

Galetti, M.; R.S. Bueno; C.S.S. Bernardo; R. Bovendorp; C.E. Steffler; P. Rubim; S.K. Kobbo; R.M. Marques; R.A. Nobre; C.I. Donatti; R.A. Begotti; F. Meirelles; A. Giacomini; A.G. Chiarello \& C.A. Peres. 2009. Conservation priorities and regional scale determinants of medium and large mammal abundance across the Atlantic forest biome. Biological Conservation 142: 1229-1241.

Genini, J.; M. Galetti \& L.P.C. Morellato. 2009. Fruiting phenology of palms and trees in an Atlantic rainforest landbridge island. Flora 204: 131-145.

Guimaraes, P. R.; J. Jose; M. Galetti \& J.R. Trigo. 2003. Quinolizidine alkaloids in Ormosia arborea seeds inhibit predation but not hoarding by agoutis (Dasyprocta leporina). Journal of Chemical Ecology 29: 1065-1072.

Guimarães, P.R.; M. GaletTi \& P. Jordano. 2008. Seed dispersal anachronisms: rethinking the fruits extinct megafauna ate. PloS ONE 3: 1745.

HallwaChs, W. 1986. Agoutis (Dasyprocta punctata): the inheritors of guapinol (Hymenaea courbaril: Leguminosae), p. 285-304. In: A. Estrada \& T.H. Fleming (Eds). Frugivores and seed disperal. Dordrecht, Dr W. Junk. Publ.

Jansen, P.A.; F. Bongers \& L. Hemerik. 2004. Seed mass and mast seeding enhance dispersal by a Neotropical scatter-hoarding rodent. Ecological Monographs 74: 569-589.

JoRge, M. 2008. Effects of forest fragmentation on two sister genera of Amazonian rodents (Myoprocta acouchy and Dasyprocta leporina). Biological Conservation 141: 617-623.

Morellato, L.P.; D.C. Talora; A. Takahasi; C.S.C. Bencke; E.C. Romera \& V. Zipparro. 2000. Phenology of Atlantic rain forest trees: a comparative study. Biotropica 32: 811-823.

Muller-Landau, H.C. 2007. Predicting the long-term effects of hunting on plant species composition and diversity in tropical forests. Biotropica 39: 372-384.

Peres, C.A. 2000. Evaluating the Impact and Sustainability of Subsistence Hunting at Multiple Amazonian Forest Sites, p. 31-56. In: J.G. Robinson \& E.L. BENNETT (Eds). Hunting for Sustainability in Tropical Forests. New York, Columbia UniversityPress.

Peres, C.A. \& C. Baider. 1997. Seed dispersal, spatial distribution and population structure of Brazilnut trees (Bertholletia excelsa) in southeastern Amazonia. Journal of Tropical Ecology 13: 595-616.

Pimentel, D.S. \& M. Tabarelli. 2004. Seed dispersal of the palm Attalea oleifera in a remnant of the Brazilian Atlantic Forest. Biotropica 36: 74-84.

Terborgh, J.; G. Nuñes-Iturri; N.C.A. Pitman; F.H.C. Valverde; P. Alvarez; V. Swamy; E.G. Pringle \& C.E.T. Paine. 2008. Tree recruitment in an empty forest. Ecology 89: 1757-1768.

VANDER WALL, S.B. 1990. Food hoarding in animals. University of Chicago Press, Chicago.

WRIGHT, S.J. 2003. The myriad consequences of hunting for vertebrates and palnts in tropical forests. Perspectives in Plant Ecology Evolutions and Systematics 6: 73-86.

Wright, S.J.; H. Zeballos; I. Domíngues; M.M. Gallardo; M.C. MoRENo \& R. IBÁÑEz. 2000. Poachers alter mammal abundance, seed dispersal, and seed predation in a Neotropical forest. Conservation Biology 14: 227-239.

Submitted: 27.VIII.2009; Accepted: 03.V.2010.

Editorial responsibility: Marcio R. Pie

ZOOLOGIA 27 (3): 472-476, June, 2010 